\title{
Active System for Electromagnetic Perturbation Monitoring in Vehicles
}

\author{
Adrian Marian Matoi and Elena Helerea \\ Transilvania University of Brasov, Eroilor Bvd. 29, 500036 Brasov, Romania \\ matoi@unitbv.ro, helerea@unitbv.ro
}

\begin{abstract}
Nowadays electromagnetic environment is rapidly expanding in frequency domain and wireless services extend in terms of covered area. European electromagnetic compatibility regulations refer to limit values regarding emissions, as well as procedures for determining susceptibility of the vehicle. Approval procedure for a series of cars is based on determining emissions/immunity level for a few vehicles picked randomly from the entire series, supposing that entire vehicle series is compliant. During immunity assessment, the vehicle is not subjected to real perturbation sources, but exposed to electric/magnetic fields generated by laboratory equipment. Since current approach takes into account only partially real situation regarding perturbation sources, this paper proposes an active system for determining electromagnetic parameters of vehicle's environment, that implements a logical diagram for measurement, satisfying the imposed requirements. This new and original solution is useful for EMC assessment of hybrid and electrical vehicles.
\end{abstract}

Keywords: Electromagnetic environment, electromagnetic emissions, European legislation, automotive safety, active measurement system.

\section{Introduction}

Modern vehicles are based on a large number of command and control systems, data acquisition and processing units. Output data from certain systems represent input data for others. Based on data received from sensors, actuators control input/output parameters for different systems, directly or through feedback loops [1]. According to the controlled system, sensors and actuators can be considered critical elements for vehicle functioning. Due to the complexity and number of sensors/actuators, processing and command units, electromagnetic compatibility (EMC) problems have diversified in two directions:

- Signal integrity and implicitly, the integrity of data transmitted between units is affected by perturbation sources situated in their electromagnetic environment;

- Besides existing electromagnetic noise, vehicles raise the perturbation level of the electromagnetic environment.

Nowadays EMC testing methods for vehicles imply basically measuring emissions level and applying an electromagnetic field on the vehicle to check its immunity, in an anechoic chamber or free space [2]. The development and testing of safety-related and 
safety critical systems has received considerable attention from the technical, academic and standards-making safety community in recent years, since safety methodology and its development in other standards show a lack in understanding the correct way to deal with this issue [3].

Current paper presents the concept of a real time emissions measurement system designed to be mounted in vehicles. The proposed system is described and experimental determinations under different conditions are performed.

\section{Contribution to Technological Innovation}

Technological innovation is the key factor for the development of a knowledge based society. Nowadays requirements related to a proper functioning of vehicles impose the development of innovative techniques and systems for automotive EMC assessment.

The paper contributes to technological innovation through the design and implementation of a new active system for electromagnetic perturbation monitoring in vehicles. This system is capable to measure the parameters of electromagnetic environment from the vehicle, automatic adjust measurement system's parameters and warn the driver in case of EMC limit overpass, increasing therefore the functional safety of the vehicle.

\section{EMC Automotive Testing Methods Analysis}

The increase of electric and electronic devices involved in technical domains, including automotive, has led to the development of a large number of EMC testing methods [2], [3], [4], [5], [6]. The requirements for engine vehicles regarding EMC are stated in 2004/104/EC EU directive, covering both emissions and immunity, for vehicles produced/traded in EU. The requirements refer both to radiated and conducted perturbation.

Electric and electronic systems functioning at frequencies higher than $30 \mathrm{MHz}$ (or whose harmonics are higher than $30 \mathrm{MHz}$ ) are considered possible radiation sources. In the far field region, electromagnetic field can be characterized either by electric field strength or by magnetic field strength that are coupled by medium's wave impedance [7]. Since electric field strength measurement is more precise in high frequency domain and magnetic field strength can be determined from wave's impedance formula, electromagnetic field is characterized by electric field strength. Due to the large number of electronic components functioning at high frequencies, in the following are analyzed the requirements regarding radiated emissions of vehicles and electronic subassemblies (ESA).

\subsection{Emissions}

In order to determine emissions radiated by ESAs, a series of settings have to be performed. Recommended environment is an anechoic chamber or an open space, 'quiet' from electromagnetic point of view [2]. In order to obtain conclusive results, an offset in amount of $6 \mathrm{~dB}$ is defined between noise level and limit line for the measured 
device. Resolution bandwidth of the spectrum analyzer is $120 \mathrm{kHz}$, for the entire frequency domain: $30 \mathrm{MHz}-1 \mathrm{GHz}$.

For narrowband perturbation measurement, an average detector is utilized. The distance between measurement antenna and ESA is $3 \mathrm{~m}$.

In comparison to ESAs, the emissions from vehicles are measured at a distance of $10 \mathrm{~m}$, utilizing a 'quasi-peak' detector for broadband emissions and an average detector for narrowband emissions. Limit lines for both broadband and narrowband emissions from vehicles are presented in Fig. 1.

a)

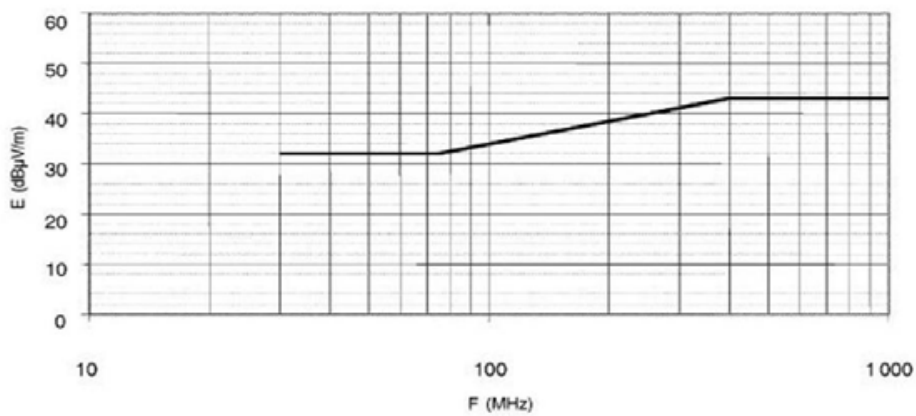

b)

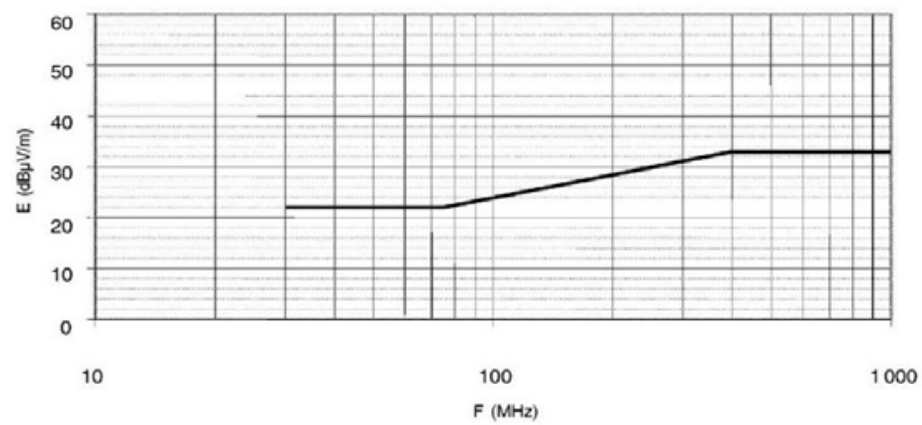

Fig. 1. Electromagnetic emission limit lines for vehicles according to 2004/104/EC directive: a) broadband; b) narrowband [2]

The module of electric field strength in frequency domain $75-400 \mathrm{MHz}$ :

$$
E=32+15,13 \log (F / 75)
$$

in the case of broadband emissions and:

$$
E=22+15,13 \log (F / 75)
$$

in the case of narrowband emissions, where: $E$ - electric field strength module $[\mathrm{dB} \mathrm{mV} / \mathrm{m}], F$ - frequency [MHz]. Broadband signal is considered the signal whose frequency bandwidth is larger than bandwidth of the measurement device [7]. The limit line for narrowband emissions is more restrictive than the one for broadband emissions. 


\subsection{Immunity}

Testing methods for immunity of vehicles and their ESAs are also specified in the directive. It consists of exposing the vehicle and its separate ESAs to electromagnetic fields and verifying their functionality during exposure. Device under test (DUT) state and testing conditions for both vehicle and ESAs are specified in Table 1.

Table 1. Testing conditions for automotive ESAs and vehicles according to 2004/104/EC directive

\begin{tabular}{|c|c|c|}
\hline DUT & ESA testing & Vehicle testing \\
\hline $\begin{array}{l}\text { 1. State of } \\
\text { DUT }\end{array}$ & $\begin{array}{l}\text { - switched on, in normal } \\
\text { operating conditions } \\
\text { - if the ESA contains more units, } \\
\text { interconnection cables should be } \\
\text { the ones intended for use in } \\
\text { vehicle }\end{array}$ & $\begin{array}{l}\text { - engine turns wheels at a } 50 \mathrm{~km} / \mathrm{h} \\
\text { speed } \\
\text { - all EMC related equipment turned } \\
\text { on }\end{array}$ \\
\hline $\begin{array}{l}\text { 2. Testing } \\
\text { conditions }\end{array}$ & $\begin{array}{l}\text { - the field is applied using the } \\
\text { substitution method in the range } \\
20 \text { - } 2000 \mathrm{MHz} \\
\text { - applied signal is: } 80 \% \mathrm{AM} \\
\text { modulation, } 1 \mathrm{kHz} \text { in frequency } \\
\text { range } 20 \text { - } 800 \mathrm{MHz} \text { and PM } \\
\text { modulation, t on } 577 \mathrm{~ms} \text {, period } \\
4600 \mathrm{~ms} \text { in frequency range } 800 \\
\text { - } 2000 \mathrm{MHz} \\
\text { - dwell time: } 250 \mathrm{~ms} \\
\text { - highest severity level } 100 \mathrm{~V} / \mathrm{m}\end{array}$ & $\begin{array}{l}\text { - the field is applied using the } \\
\text { substitution method in the range } 20- \\
2000 \mathrm{MHz} \\
\text { - applied signal is: } 80 \% \mathrm{AM} \\
\text { modulation, } 1 \mathrm{kHz} \text { in frequency range } \\
20-800 \mathrm{MHz} \text { and } \mathrm{PM} \text { modulation, } \mathrm{t} \\
\text { on } 577 \mathrm{~ms} \text {, period } 4600 \mathrm{~ms} \text { in } \\
\text { frequency range } 800-2000 \mathrm{MHz} \\
\text { - only vertical polarization testing is } \\
\text { required } \\
\text { - dwell time: } 250 \mathrm{~ms} \\
\text { - highest severity level } 100 \mathrm{~V} / \mathrm{m}\end{array}$ \\
\hline
\end{tabular}

The testing methods for ESAs and vehicles differ especially through distance between DUT and antenna and the requirement regarding polarization of the test field.

\subsection{Critical Analysis of Current Approach}

Although EMC testing technique has advanced, there are still some aspects that have to be taken into account for EMC assessment:

- From an entire vehicle series produced, only a couple are EMC tested;

- Tests are performed in a laboratory or "quiet" free space, where perturbation sources are artificially simulated;

- Electromagnetic environment is rapidly evolving regarding number and type of perturbation sources [8];

- Mobility of sources is not taken into account, far field and near field conditions not being therefore considered.

EMC achievement method for vehicles could be improved by installing an EMC monitoring system on each vehicle capable to: 
- Measure and process parameters of electromagnetic environment;

- Adjust system's measuring parameters actively;

- Warn the driver in case of detecting powerful perturbation sources, capable to affect vehicle's functionality;

- Interact with communication and control systems of the vehicle, in order to increase the safety level when necessary.

\section{Active System for EMC Monitoring of Vehicle's Environment}

\subsection{The System Concept}

The concept has been developed to overpass existing limitations. Logical diagram of the system is presented in Fig. 2.

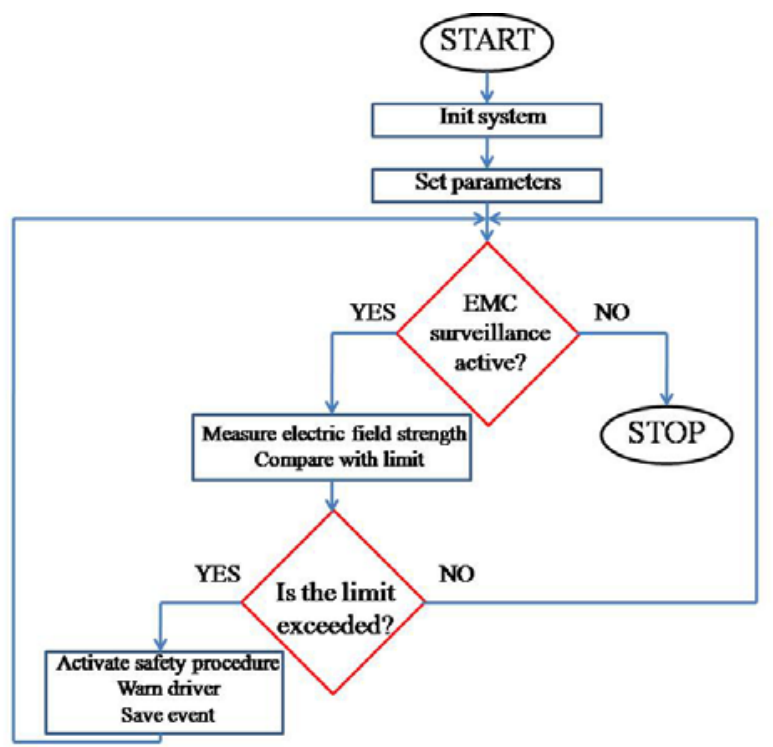

Fig. 2. Active electromagnetic emission measurement system logical diagram

The measurement system has the following functions:

- To initiate the software platform, allowing to measure and process data related to electromagnetic field parameters;

- Set the parameters of devices, like: type of measurement, frequency domain, resolution bandwidth, threshold, limit line and so on;

- Check if EMC surveillance is activated by the command computer or the driver;

- Perform field measurement and compare it to the pre-established limit line;

- In case the limit is exceeded, the system activates a safety procedure through the command computer of the vehicle, warns the driver and saves data like position of 
the vehicle (supposing that the vehicle has a GPS system), time and values that exceed the limit line.

A good functioning of the system implies a bidirectional connection between the EMC surveillance system and command computer of the vehicle that can be achieved, for example, by means of a bus system or a modern interface like USB. The major advantage of this implementation is the flexibility concerning measurement parameters, interconnectivity, upgrades and implementation of future standards regarding EMC requirements. The safety of passengers and other participants to the traffic is increased considerably both by warning the driver in case of unexpected high field strength and activating safety procedures like: increasing voltage on communication bus lines, activating a supplementary communication system for safety related devices of the vehicle (steering, braking, engine control).

\subsection{Implementation of the System}

The concept has been implemented using a spectrum analyzer, antenna and a portable computer. The components are connected as shown in Fig. 3.

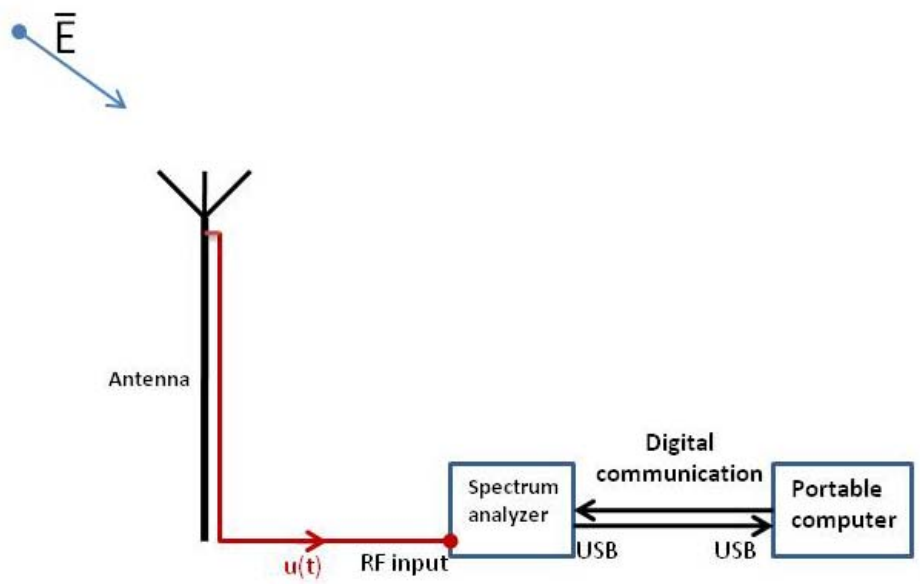

Fig. 3. Components connection diagram

The components of the system are:

- AAronia Spectran HF 6080 spectrum analyzer having the following characteristics: frequency domain: $10 \mathrm{MHz}-8 \mathrm{GHz}$; Resolution bandwidth: $1 \mathrm{kHz}-50 \mathrm{MHz}$; Input signal range: $-160 \mathrm{dBm}-+10 \mathrm{dBm}$; Accuracy: +/- $2 \mathrm{~dB}$; Portable (battery), USB connection port.

- AAronia Hyperlog 7060 electric field measurement antenna having the following parameters: Directional; Factory calibration frequency range: $700 \mathrm{MHz}-6 \mathrm{GHz}$; Gain: typically $5 \mathrm{dBi}$; Antenna factor: $26-41 \mathrm{~dB} / \mathrm{m}$.

- HP Compaq 6710 b portable computer running the measurement software. 


\section{Experimental Determinations}

Measurements have been performed in order to determine whether the system is able to detect in real time perturbation sources, while the vehicle is running. The system has been mounted in an ALFA Romeo 156 vehicle. The antenna has been placed on the top of the vehicle/ inside the passenger's compartment. The measurement software has been started and measurements have been performed while the vehicle was driven inside and outside Brasov city. Measurement system's parameters were: Frequency domain: $80 \mathrm{MHz}-8 \mathrm{GHz}$; Resolution bandwidth: $1 \mathrm{MHz}$, due to the wide frequency domain; Scanning time: $50 \mathrm{~ms}$; Peak detector.

In Fig. 4 is shown one of the performed measurements, when the antenna was placed inside passenger's compartment.

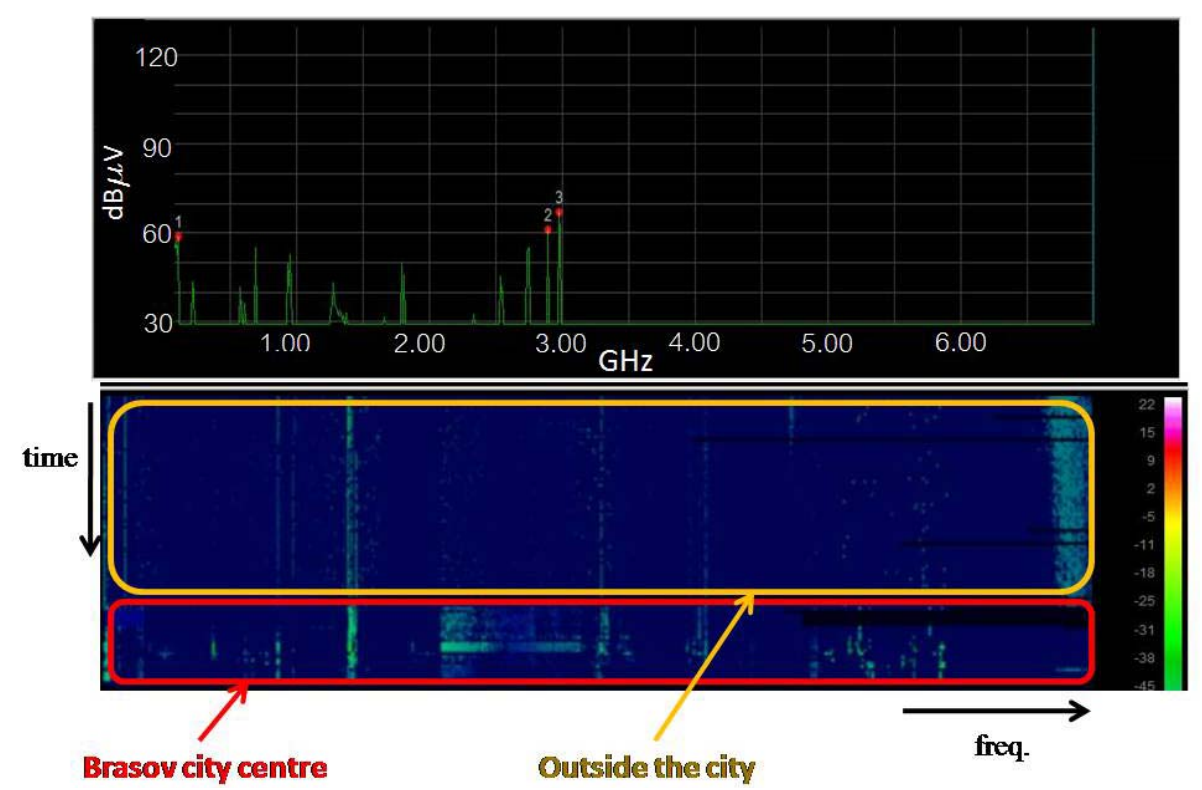

Fig. 4. Electric field strength surveillance while a vehicle is driven outside and inside Brasov city

The experimental determinations show that the number of electromagnetic field sources is larger inside Brasov city in comparison to its surroundings. Highly populated areas have the following characteristics from electromagnetic environment's point of view: available communication services are various and numerous (and offer broadband services), radio and TV antennas are situated in the vicinity and the number of mobile perturbation sources (cellular phones, vehicles) is higher. 


\section{Conclusions}

The evolution of electromagnetic environment imposes an active method for monitoring its parameters and adjusting the running conditions of the vehicles, in order to increase passengers and traffic safety.

The developed active system for electromagnetic perturbation monitoring is capable to measure and process data related to vehicle's electromagnetic environment in real time, increasing therefore the safety of vehicle's functioning. Unpredicted perturbation sources are detected and data regarding their parameters would be available in case the pre-established limit lines are exceeded.

Although the prices of EMC equipment have been high until recently, modern technology will allow a good integration cost - low cost spectrum analyzers are already available on the market - taking into consideration the advance of EMC measurement technique and reduction of integrated circuits dimensions. The solution proposed does not imply special education for the user, the only task for the driver in case of detecting perturbing fields being to stop the vehicle (the user can be warned by a visual/audio signal). The system is capable to automatically save data about events and transfer it to a computer when the periodical service is attended.

Performance can be increased by including in the measurement system an isotropic antenna and a parallel processing spectrum analyzer. The development of a wide spread EMC measurement system will allow a better characterization of the electromagnetic environment. Position of the measurement antenna remains an open subject.

\section{References}

1. Ribbens, W.B.: Understanding Automotive Electronics, 6th edn. Newnes Publishing House, USA (2003)

2. European Union Commission: Commission directive 2004/104/EC, Official Journal of the European Union (2004)

3. Armstrong, K.: Review of Progress with EMC-Related Functional Safety. In: 2003 IEEE Symposium on EMC proceedings (2003)

4. Roman, B., Enache, V.: Automobilul modern (Modern Vehicle). Transilvania University Publishing House, Brasov (2008)

5. Heirman, D., Stecher, M.: A History of the Evolution of EMC Regulatory Bodies and Standards. In: Proceedings of EMC Zurich 2005 Symposium, Zurich, pp. 83-94 (2005)

6. O'Hara, M.: A generic automotive (TIER1) EMC Test Standard, In: Proceedings of Automotive EMC 2006 Driving the New Directive Conference, Birmingham (2006)

7. Williams, T.: EMC for Product Designers, 4th edn. Newness Publishing House, Cornwall (2007)

8. Costea, M.: Methods and Proceedures for Assurance of EM Imunity/Metode şi Mijloace de Asigurare a Imunității Electromagnetice/. AGIR Publishing House, Bucharest (2006) 